\title{
A RARE VARIATION OF GREAT SAPHENOUS VEIN: A CASE REPORT
}

\section{Rajeev Panwar ${ }^{1}$, Dharmaraj W. Tamgire *2, Yogesh A. Sontakke ${ }^{3}$, Rajasekhar SSSN ${ }^{4}$.}

1 Junior Resident, Department of Anatomy, Jawaharlal Institute of Postgraduate Medical Education and Research, Pondicherry, India.

${ }^{* 2,3,4}$ Associate Professor, Department of Anatomy, Jawaharlal Institute of Postgraduate Medical Education and Research, Pondicherry, India.

\section{ABSTRACT}

Variations of great Saphenous Vein are clinically important because of its role in varicose veins recurrence and as application as an autograft for coronary angioplasty. The incidence of Great Saphenous Vein duplication cited in medical literature ranges from $0.97 \%$ to $49 \%$. The present case discusses a rare duplicated and mesh appearance of Great Saphenous vein and its clinical applications. Great Saphenous Vein and its duplication, both started separately from dorsal venous arch of left foot in a 60 years old male cadaver during routine dissection. They were connected by three venous communications during their course and drained as a single vein at saphenofemoral junction after uniting at the level of apex of femoral triangle. Thorough understanding of anatomical variations of great saphenous vein and its tributaries are important ensuring the effective diagnosis and treatment of varicose veins.

KEY WORDS: Great Saphenous Vein, Variation, Duplication, Mesh, Varicose Vein.

Address for Correspondence: Dr. Dharmaraj W. Tamgire, Associate Professor, Department of Anatomy, Jawaharlal Institute of Postgraduate Medical Education and Research, Pondicherry605006, India. E-Mail: dtamgire@gmail.com

Access this Article online

Quick Response code

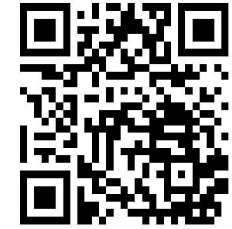

DOI: $10.16965 /$ ijar.2018.169
Journal Information

International Journal of Anatomy and Research

ICV for 2016 ISSN (E) 2321-4287 | ISSN (P) 2321-8967

90.30

https://www.ijmhr.org/ijar.htm

DOI-Prefix: https://dx.doi.org/10.16965/ijar

\section{Article Information}

Received: 27 Feb 2018

Peer Review: 28 Feb 2018

Revised: None
Accepted: 05 Apr 2018

Published (O): 05 May 2018

Published (P): 05 May 2018

\section{INTRODUCTION}

Venous anatomy of lower limb is infamous for its variations because of its impact on clinical and surgical outcome. Vena Saphania Magna or Great saphenous vein (GSV) is a superficial, preaxial vein of the lower limb, which may show variations in terms of formation, termination, and various patterns of tributaries. Normally it begins as the medial marginal vein of the foot and ends in the femoral vein below the inguinal ligament. During its course, it ascends in front of the tibial malleolus and obliquely crosses the lower part of the medial surface of the tibia to its medial border and ascends to the knee. It reaches the saphenous opening in the thigh and drains into the femoral vein [1].
Though the literature suggests that duplication of GSV is present in $2-10 \%$ of cases, true duplication as defined by Union International de Phlébologie (UIP) in 2006 is present in $1.6-2 \%$ of cases [2]. Anatomical variations of GSV derive its attention owing to its implication in recurrence of varicose veins and autografts for arterial bypass surgery [3].

In this case report a rare case of duplication with meshed appearance of GSV and its clinical significance.

\section{CASE REPORT}

The present variation was noted on left lower limb during the routine dissection classes for undergraduate students at JIPMER, Puducherry 
in a 60 years old male cadaver. The GSV and Duplicated GSV were dissected from its formation to termination in femoral vein. Diameters of all veins were noted with Vernier calliper and the larger division was considered as continuation. Three venous channels were seen emerging out from dorsal venous network of foot. Medial channel from the most medial end of dorsal venous arch as normal GSV. Middle channel formed by veins draining lateral side of great toe, second, third and medial side of fourth toe. Lateral venous channel was derived from veins draining lateral side of fourth toe and fifth toe. The medial venous channel follows the normal course for Great saphenous vein and will subsequently be called as normal GSV. The middle and lateral venous channel ascend to the level of medial malleolus and joined with each other to form duplicated GSV. (Fig. 1)

Both the veins ascend along medial border of tibia in leg, then along the posteromedial aspect of knee joint parallel to each other, wherein duplicated GSV coursing anterior to GSV. At the level of apex of femoral triangle, both GSV and duplicated GSV joined to form a single vein that drained into the femoral vein after passing through saphenous opening. In middle third of leg both the veins communicate with each other by numerous venous channels giving the typical plexiform appearance. (Fig. 2) GSV $(3.77 \mathrm{~mm})$ ascends approximately $20 \mathrm{cms}$ in leg and divides into anterior $(2.29 \mathrm{~mm})$ and posterior $(2.46 \mathrm{~mm})$ divisions. It gives off a perforator in the middle of leg just after its division. Above knee it receives posteromedial vein of thigh.

Immediately after formation, the duplicated GSV $(3.5 \mathrm{~mm})$ and GSV were seen to be connected by a communicating vein (fig.) which receives two deep perforating veins. (Fig. 1) Duplicated GSV runs anterior to GSV throughout its course. Approximately $7 \mathrm{cms}$ proximal to its formation it received medial marginal vein from medial aspect of foot and a lateral tributary from lower anterior aspect of leg. About $6 \mathrm{cms}$ proximal to draining tributaries, the vein gives off a second communicating vein $(1.84 \mathrm{~mm})$ which drained into GSV about $11 \mathrm{cms}$ distal to its division. This vein received a tributary from posterior aspect of leg. About $5 \mathrm{cms}$ proximal to second commu- nicating vein, duplicated GSV again gives off a third communicating vein $(1.72 \mathrm{~mm})$ joining the GSV just after its division. About $10 \mathrm{cms}$ proximal to third communication it receives the anterior division of GSV. Two perforators were observed in relation to duplicated GSV, one in middle of leg and another at the knee joint. It receives one tributary in middle of leg from anterior side and another tributary above knee as anterolateral vein of thigh. The above noted communications can be noted in fig. 2 .

Fig. 1: Formation of GSV and duplicated GSV (A-Actual dissection, B- Schematic representation).
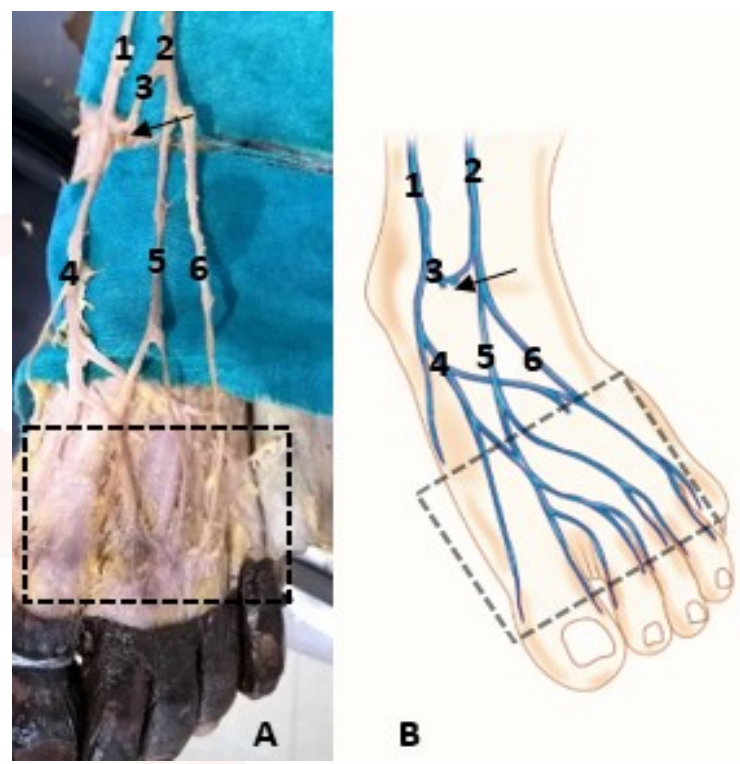

(1- GSV/Great Saphenous Vein, 2- Duplicated GSV, 3- communicating vein, 4- medial, 5- Middle, 6- lateral venous channel from Dorsal venous arch, Arrow head- perforators, Dotted box- Dorsal venous arch)

Fig. 2: Multiple communications between GSV and Duplicated GSV (A-Actual dissection, B- Schematic representation).

(1- GSV/Great Saphenous Vein,

2- Duplicated GSV, 3communicating vein,

4,5 and 6communicating veins, Arrowheadstributaries)
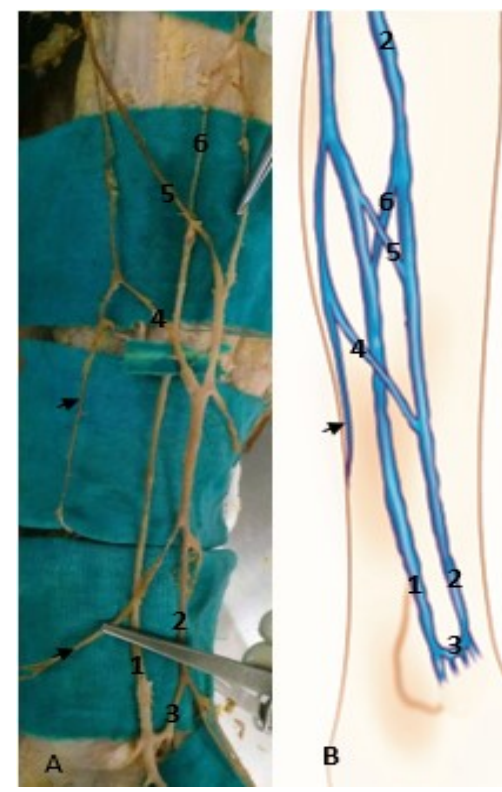


\section{DISCUSSION}

GSV is venerated by clinicians owing to its distinctive anatomical characteristics. GSV is a single, long and readily accessible vein with significant amount of smooth muscles and elastic fibres making it as a popular vein for venous graft used for coronary artery bypass surgery [4].

Reports of duplicated GSV according to the criteria given by Union International de Phlébologie (UIP) in 2006 are rare (1.6\%-2\%). Moreover, duplication from formation to the thigh are extremely uncommon [5].

According to Corrales NE et al (2002) a double saphenous venous system of the entire lower limb is rare, with an incidence of $0.97 \%$. In duplicated or double saphenous venous system, both the veins started independently from the dorsum of the foot crossed the calf region and terminated in the anterior thigh region [6]. Motwani et al (2013) in their cadaveric study involving 56 lower limbs reported 8.9\% GSV duplication, wherein a complete duplication was observed in $3.57 \%$ [7]. GSV duplication is observed more frequent in males than females and is more common unilaterally and in the thigh than in leg [6]. In the present case we observed a unilateral, left sided, duplication of GSV, from its formation to the midthigh region in a 60 years old male cadaver. Vijaywargiya et al (2016), in their cadaveric study on 30 lower limbs had classified GSV duplications into 7 patterns. They concluded that the duplications were present unilaterally, more in the thigh region, commoner in females and were commoner in the right limb [8]. Neha Rai et al (2017) reported 40\% GSV duplications with maximum number of duplication in ankle region and least number of duplications in knee region [9]. None of the previous studies reported the pattern observed in the present case. Relatively similar morphological configurations were observed by Talalwah et al (2014) and Abhinitha et al (2017) [10-11].

Gad et (2013) reported that $15.2 \%$ of patients with recurrent varicose were having a double long saphenous venous system [12]. GSV plays an important role in the venous return of the lower extremity because of numerous tributaries and it has relations with deeper veins. The long, superficial course of vein against gravity makes this vein vulnerable to varicosities, aggravated by predisposing factors like professions involving standing for long duration and old age. The network of tributaries, dividing and anastomosing divisions of the GSV and duplicated GSV in calf region presents a great clinical challenge in treating the varicose veins [13].

Knowledge of origin of GSV, its tributaries, termination and its variations becomes pertinent in the conservative approach, sclerotherapy, ultrasound-guided sclerotherapy, and ligation of saphenofemoral junction with or without venous stripping for varicose veins. Consequently, identification of anatomical variations play an important role in increasing the success and efficacy of surgical treatments and in decreasing the recurrence rates Awareness of anatomical variations involving GSV and its tributaries is an essential prerequisite for duplex ultra-sonographic imaging, MRI and CT Venography [14].

\section{Conflicts of Interests: None}

\section{REFERENCES}

[1]. Padavinangadi A, Kumar N, Swamy RS, Satheesha NB, Mohandas Rao KG. Unilateral Double Great Saphenous Vein: A Clinically Significant Case Report. J Cardiovasc Echogr. 2015 Oct-Dec;25(4):116118. doi: 10.4103/2211-4122.172491.

[2]. Kockaert M, de Roos KP, van Dijk L, Nijsten T, Neumann $M$. Duplication of the great saphenous vein: a definition problem and implications for therapy. Dermatol Surg. 2012 Jan;38(1):77-82. doi: 10.1111/ j.1524-4725.2011.02154. x. Epub 2011 Sep 14.

[3]. Mohammed A Gad, Aly Saber, ${ }^{1}$ and Emad N Hokkam. Assessment of Causes and Patterns of Recurrent Varicose Veins After Surgery. N Am J Med Sci. 2012 Jan; 4(1): 45-48. doi: 10.4103/1947-2714.92905

[4]. Aydýn Kurt, Yeliz Aktürk, Baki Hekimoðlu. A rare anatomical variation of the greater saphenous vein. Case report. Med Ultrason 2014, Vol. 16, no. 1, 6062 DOI: 10.11152/mu.2014.2066.161.ak1ya2

[5]. Kockaert M, De Roos KP, van Dijk L, Nijsten T, Neumann M. Duplication of the great saphenous vein: a definition problem and implications for therapy. Dermatol Surg. 2012 Jan;38(1):77-82. doi: 10.1111/ j.1524-4725.2011.02154. x. Epub 2011 Sep 14.

[6]. Corrales NE, Irvine A, McGuinness CL, Dourado R, Burnad KG. Incidence and pattern of long saphenous vein duplication and its possible implication for recurrence after varicose vein surgery. British Journal of Surgery.2002;89:323-326 
[7]. Motwani R, Jain P. Duplication of great saphenous veinanatomical description and its clinical implications. International Journal of Biological \& Medical Research 2013;4(3):3372-4.

[8]. Vijaywargiya M, Jain M, Devpujari R. Morphological variations in duplication of great saphenous vein. J. Evolution Med. Dent. Sci. 2016;5(59):40524055, DOI: $10.14260 /$ jemds/2016/928

[9]. Neha Rai, Sheema Nair*, Naresh Thanduri, Rajeev Joshi. Variations of great saphenous vein: a cadaveric study in central Indian population. International Journal of Research in Medical Sciences. 2017 Jul;5(7):2883-2886

[10]. Talalwah WA, Soames R. A duplicated great saphenous vein and clinical significance for verocosity. Rev Arg de Anat Clin. 2014;6(1): 43-46

[11]. Padavinangadi A, Kumar N, Swamy RS, Satheesha NB, Mohandas Rao KG. Unilateral double great saphenous vein: A clinically significant case report. J Cardiovasc Echography 2015; 25:116-8.
[12]. Gad MA, Saber A, Hokkam EN. Assessment of Causes and Patterns of Recurrent Varicose Veins After Surgery. North American Journal of Medical Sciences. 2012;4(1):45-48. doi:10.4103/19472714.92905.

[13]. Baliyan V, Tajmir S, Hedgire SS, Ganguli S, Prabhakar AM. Lower extremity venous reflux. Cardiovascular Diagnosis and Therapy. 2016;6(6):533-543. doi:10.21037/cdt.2016.11.14.

[14]. Tavlapoðlu M, Güler A, Gürbüz HA, Tanrýseven M, Kürklüoðlu M, Yepil FG. Anatomical variations of saphenofemoral junction encountered during venous surgery. Journal-Cardiovascular Surgery 2013; 1: 5-7.

How to cite this article:

Rajeev Panwar, Dharmaraj W. Tamgire, Yogesh A. Sontakke, Rajasekhar SSSN. A RARE VARIATION OF GREAT SAPHENOUS VEIN: A CASE REPORT. Int J Anat Res 2018;6(2.2):5246-5249. DOI: 10.16965/ijar.2018.169 